\title{
PROCESSOS DE MIDIATIZAÇ̃̃O DA PEQUENA INFÂNCIA: UM ESTUDO EXPLORATÓRIO COM CRIANÇAS DE 4 E 5 ANOS
}

\author{
PROCESSES OF MEDIATIZATION OF EARLY CHILDHOOD: AN EXPLORATORY \\ STUDY OF FOUR TO FIVE-YEAR-OLD CHILDREN \\ PROCESOS DE MEDIATIZACIÓN DE LA PEQUEÑA INFANCIA: UN ESTUDIO \\ EXPLORATORIO CON NIÑOS DE 4 Y 5 AÑOS.
}

Nádia Jane de Sousa**

http://orcid.org/OOOO-0002-3648-4559

\begin{abstract}
REVISTA PEDAGÓGICA
Revista do Programa de Pós-graduação em Educação da Unochapecó | ISSN 1984-1566 Universidade Comunitária da Região de Chapecó | Chapecó-SC, Brasil Como referenciar este artigo: SOUSA, N. Processos de midiatização da pequena infância: um estudo exploratório com crianças de 4 e 5 anos. Revista Pedagógica, Chapecó, v. 22, p. 1-17, 2020. DOI: https://doi.org/10.22196/rp.v22io.5494
\end{abstract}

Resumo: Este estudo pretende discutir o processo de midiatização da infância a partir de um estudo exploratório com crianças de quatro e cinco anos em instituições públicas brasileiras. O trabalho objetiva identificar elementos desse processo que estão presentes entre crianças pré-escolares. Pretende também verificar, a partir das interações em seus ambientes formais de educação, de que modo os seus cotidianos se conjugam com os meios de comunicação e como incorporam conteúdos midiáticos nas formas de ser/estar criança. A partir de atividades diversas com a participação ativa dos grupos, foi possível identificar a presença de elementos de midiatização em seus modos de brincar, nos brinquedos que possuem e nos que desejam adquirir, na relação que estabelecem com as mídias eletrônicas e digitais, especialmente o YouTube, com destaque para os YouTubers.

Palavras-chave: Infância. Crianças de quatro e cinco anos. Midiatização. Mídias.

Abstract: This study aims to discuss the process of mediatization of childhood through an exploratory study of four to five-year-old children in brazilian public institutions. This project's purpose is to identify elements in that process that are present among preschool children. It also intends to verify, considering the interactions in their formal education environments, how their daily lives combine with the means of communication and how they embody mediatic content in their ways of being. Through diverse activities with an active group participation, it was possible to identify the presence of mediatization elements in their way of playing, in the toys they possess and wish to acquire, in the relation they establish with the electronic and digital media, especially YouTube, with a special focus on YouTubers.

Keywords: Childhood. Four to five-year-old children. Mediatization. Media

Resumen: Este estudio tiene como objetivo discutir el proceso de mediatización de la infancia basado en un estudio exploratorio con niños de cuatro y cinco años en instituciones públicas brasileñas. El trabajo tiene como objetivo identificar elementos de este proceso que están presentes entre los niños en edad preescolar. También tiene la intención de verificar, a partir de las interacciones en sus entornos educativos formales, cómo se combinan sus vidas diarias con los medios y cómo incorporan el contenido de los medios en las formas de ser / ser un niño. A partir de diversas actividades con la participación activa de los grupos, fue posible identificar la presencia de elementos de mediatización en sus formas de jugar, en los juguetes que tienen y en los que desean adquirir, en la relación que establecen con los medios electrónicos y digitales, especialmente el YouTube, destacando YouTubers.

Palabras-clave: Infancia. Niños de cuatro y cinco años. Mediatización. Medios de comunicación. 


\section{Introdução}

Não é possível desconsiderar a importância do universo midiático na configuração da vida social e cultural na atualidade, especificamente na vida das crianças. Pari passu com as transformações da sociedade moderna e os diferentes modos de considerar a infância nesse processo, os discursos e conteúdos dos dispositivos midiáticos dirigidos "para" e "sobre" as crianças, têm provocado ao longo da História paradoxos que contribuem para o estabelecimento de perspectivas e representações acerca das mesmas (PONTE, 2012), ora considerando-as como potentes, ora como vítimas do que é veiculado, transmitido e criado (BURCHKINGAM, 2012).

Em meio aos paradoxos, um consenso: pesquisas demonstram que a relação das crianças com as diferentes mídias é um fenômeno global, embora apresentem especificidades quanto ao uso e produção de conteúdos, a partir de seus pertencimentos geográfico, social, cultural e econômico (LEMISH, 2015; DIAS;BRITO, 2015; SAPSAGLAN, 2018; IZCI et al, 2019; PONTE et al, 2018; LIUBINIENE; KASPERAVIČIEN, 2019). Segundo Hjarvard (2013), há em curso o processo de midiatização da infância, que se manifesta de forma direta ou indireta. Na primeira, quando, através de comportamentos, demonstram simbiose entre o cotidiano infantil e os meios de comunicação (nos brinquedos, via publicidade/marketing, por exemplo); na segunda, a partir de linguagens e valores incorporados dos conteúdos aos quais têm acesso (modos de se expressar, desejos de consumo, formas de brincar, etc.).

Há de se considerar que o processo de midiatização da sociedade e em particular da infância, não é algo recente (PONTE, 2012). De uma mídia audiovisual, que, segundo Castels (1999), penetra na sociedade a partir do século XX através do cinema e do rádio, surgindo a televisão logo em seguida, passa-se a uma screen culture que incorpora vários tipos de mídia como a televisão, jogos de computador, internet, cinema, jogos eletrônicos portáteis, tablets e celulares (LEMISH, 2015). É possível afirmar que grande parte das crianças em todo o mundo têm acesso e utilizam diariamente, desde cedo, uma dessas mídias.

Considerando tal contexto, foi realizado um estudo exploratório (BABBIE, 1986), com abordagem qualitativa (MINAYO, 2001; GIL, 2008), com 50 crianças pré escolares, entre quatro e cinco anos, de duas instituições públicas, uma de âmbito municipal, outra de âmbito federal ${ }^{1}$ na cidade de João Pessoa (PB), sendo realizadas atividades em torno da literatura, pintura, diálogos e brincadeiras.

As questões que pautaram esse trabalho foram: que elementos desse processo de midiatização, estão presentes

\begin{abstract}
* Este trabalho constitui a primeira parte dos estudos pós-doutorais realizados na Universidade Nova de Lisboa/PT, sob orientação da professora Dra. Lídia Marôpo, cujo projeto inicial intitulava-se "Crianças pequenas (4 e 5 anos) e os YouTubers: da recepção à produção de sentidos".
\end{abstract} ** Doutora em Educação pela Universi-
dade Federal da Paraíba (2010), mestre
em Educação pela Universidade Federal
de Santa Catarina (2001) e graduada em
Pedagogia pela Universidade Federal da
Paraíba (1990). Professora Associada da
Universidade Federal da Paraíba, atuan-
do na formação de pedagogos na área de
Educação Infantil. E-mail: janenadia@
gmail.com

1 No Brasil, as escolas que são financiadas diretamente pela federação, possuem melhores estruturas, número reduzido de crianças por sala, melhor nível de formação dos professores (a maioria com mestrado bem como a realizar estudos para doutoramento). 
entre as crianças pré-escolares? De que modo os seus cotidianos se conjugam com os meios de comunicação? Como incorporam conteúdos midiáticos nos seus modos de ser e estar?

No Brasil, a Educação Infantil é a primeira etapa da Educação Básica, obrigatória para crianças a partir dos 4 anos de idade (BRASIL/LDB, 1996). O atendimento pode ser integral ou parcial. Nas instituições que realizam atendimento em tempo integral, as crianças passam nela de oito a dez horas por $\mathrm{dia}^{2}$; as de tempo parcial, em torno de quatro horas. Isso as fazem importantes espaços educativos (BARBOSA, 2010; KRAMER, 2006), ocorrendo ali trocas e interações diversas que, a partir do que preconiza as Diretrizes Curriculares Nacionais para a Educação Infantil no Brasil, devem ser significativas e promoverem seu desenvolvimento integral (DCNEI, 2009).

Assim, o objetivo deste trabalho é identificar elementos indicadores de uma infância midiatizada e suas imbricações nos modos de ser/estar das crianças.

Para analisar os dados, lançamos mão de dois campos de estudos: 1. Os pressupostos da Sociologia da Infância (SIROTA, 2001; DELGADO; MULLER, 2005 ) e dos Estudos da Criança (SARMENTO; PINTO, 1997), que expressam a necessidade de ver a criança em si mesma, no seu tempo presente e não como um "vir a ser", tendo seu processo de desenvolvimento inserido num quadro de múltiplas relações; 2. Os estudos sobre as mídias, especificamente acerca dos estudos da midiatização da sociedade e da cultura (HJARVARD, 2014; HEPP, 2014).

\section{Uma infância midiatizada}

A presença da criança pequena ${ }^{3}$ nas mídias digitais, seja como audiência ou agência (na publicidade, nas redes sociais, como YouTubers ${ }^{4}$, etc), tem chamado a atenção de pesquisadores (PONTE, et al., 2018; BRITO; DIAS et al, 2019). Tais trabalhos apontam que cada vez mais cedo as crianças têm acesso à aparelhos eletrônicos digitalizados, numa "tendência global de convergência crescente de brinquedos, jogos e media, tanto no mercado comercial como nas vidas quotidianas das crianças" (PONTE, et al., 2018, p.36). A presença das mídias também tem operado mudanças nas dinâmicas familiares que ora veem o acesso e uso como positivos para o desenvolvimento das crianças, ora atentam para os riscos que tais atividades contêm. A função "apaziguadora" dos meios de comunicação, especialmente da televisão e dos celulares são questões importantes apontadas pelos estudos (PONTE et al, 2018, p. 42).

Para além do acesso e uso da pequena infância ao mundo virtual, os dados apresentados nesses estudos, são
2 As instituições municipais da cidade de João Pessoa (PB), oferecem atendimento integral na Educação Infantil, atendendo um público de menor renda. O horário de atendimento é das 7 às 17 horas.

3 O termo "criança pequena" indica crianças até seis anos, idade que se encontram as crianças que frequentam a pré-escola (quatro/cinco anos e 11 meses, no Brasil). O termo é comumente usado na literatura brasileira que trata de estudos sobre a Educação Infantil (BARBOSA, 2010; KRAMER, 2006).

4 Palavra para designar não apenas "quem produzia e postava vídeos no YouTube, mas aqueles que, nessa condição, começavam a ganhar notabilidade na plataforma, por meio de números de inscritos, visualizações e rendimentos provenientes da monetização de seus canais" (TOMAZ, 2017, p. 14). 
reveladores da existência de uma sociedade midiatizada que torna-se cada vez mais dependente das mídias, sendo estas, parte integrante na estruturação das interações e das instituições sociais, como a família, a política, a religião (HJARVARD, 2015). Há para Hjarvard (2016) uma "lógica da mídia" que atua como agente estruturante sobre essas instituições, ainda que sujeita às transformações gerais da sociedade. Para o autor, tal lógica é considerada uma metáfora para dizer das "regras e recursos por meio dos quais a mídia funciona" (2016, p. 96), envolvendo aspectos normativos, tecnológicos e estéticos que ajudam a entender a relação que se estabelece entre a sociedade e a mídia e vice-versa.

Das diferentes perspectivas para entender a relação das mídias com a sociedade (SATUF et al, 2019), interessa-nos as abordagens institucional e a socioconstrutivista.

A perspectiva institucional da midiatização, entre outras questões, se caracteriza por: 1. Considerar as transformações estruturais de longa duração na relação com a mídia e outras esferas sociais; 2. Defender uma interação recíproca entre as mídias e outros campos de ação na sociedade; 3. Apresentar a mídia como uma instituição "semi-independente" (HJARVARD, 2014, p. 32) que leva suas próprias lógicas a quase todos os espaços sociais; 3. Apontar a presença das mídias no interior das instituições, tornando-se constitutivas das mesmas, a exemplo do processo de virtualização de suas práticas (na vida privada, nas relações de trabalho, na política, na religião) (HJARVARD, 2014).

A abordagem sócio construtivista, por sua vez, aponta que para se entender o processo de midiatização existente na sociedade, deve-se considerar a existência de "configurações comunicativas por meio das quais elaboramos nossos mundos midiatizados" (HEPP, 2014, p. 46. Destaques do autor). Segundo Hepp (2014), o modo como a sociedade atual, a partir de suas diferentes mídias, veiculam/constroem os modos de se comunicar (em mudança, destaca) e interagir dos pequenos "mundos sociais", precisa ser analisado. Para Hepp "as mudanças nos mundos midiatizados se tornam pesquisáveis pelas mudanças das configurações comunicativas" (2014, p. 56).

Desse modo, a relação das crianças com o consumo, com os brinquedos e as brincadeiras, com o YouTube e os YouTubers são práticas mediadas, mas permeadas por uma cultura e uma sociedade midiatizadas. É um tempo formado pela "mediação de tudo", dizem Hepp (2014, p. 46) e Livingstone (2009, p. 05).

Os pressupostos teóricos apresentados nos ajudam a compreender que o processo de midiatização da infância ocorre a partir de uma interação entre os aspectos macro e 
micro sociais. Nesse sentido, a partir destes "mundos midiatizados" é possível entender as mudanças que ocorrem nas formas de ser e de pensar a criança na atualidade.

\section{Metodologia}

Ao se buscar compreender a relação entre a infância e as mídias, há que considerar três elementos: o contexto, as crianças e o conteúdo (tipo de mídia, o que é veiculado, o que é acessado, etc.) (LEMISH, 2015).

Com o objetivo de identificar elementos indicadores de uma infância midiatizada, bem como verificar de que modo eles estão presentes nas formas de ser/estar das crianças, foram realizados encontros e observadas as interações presentes em dois grupos de crianças de quatro e cinco anos em duas instituições de Educação Infantil ${ }^{5}$.

Para o planejamento do trabalho, nos guiamos pelos seguintes pressupostos da Sociologia da Infância: 1. Consideração das crianças como atores sociais e produtores de cultura; 2. Que elas atribuem sentidos e significados próprios às situações que vivenciam; 3. Nas interações que estabelecem entre seus pares e entre os adultos não só reproduzem, mas produzem a cultura e a sociedade em que estão inseridas, numa "reprodução interpretativa" (SARMENTO; PINTO, 1997; CORSARO, 2002; SIROTA, 2001).

Nessa direção, foram realizadas atividades a partir de diálogos com as crianças, em grupo ou individualmente, bem como observações de suas interações com brinquedos diversos. As mesmas vivências, com suas devidas adaptações, foram feitas com cada grupo de crianças, por idade, portanto, dois grupos em cada instituição.

Quanto ao contexto, a primeira instituição visitada pertence à Rede Municipal de Ensino da cidade de João Pessoa/PB (Instituição "M”), que atende 96 crianças, tendo em média 25 por sala. A estrutura física desse Centro de Referência em Educação Infantil (CREI) ${ }^{6}$ é pequena, não havendo espaços amplos e materiais diversificados para usufruto das crianças e das professoras ${ }^{7}$. Normalmente, a rotina diária gira em torno de cuidados de higiene, alimentação, ida ao parque (por grupo de crianças) e atividades dirigidas em torno da escrita de números e letras do alfabeto e pinturas. As instituições municipais seguem as orientações pedagógicas da Secretaria de Educação do Município, que apontam temas a serem desenvolvidos ao longo de cada bimestre, ficando a critério de cada instituição criar seus próprios projetos.

A segunda Instituição pertence à Rede Federal de Ensino, atendendo crianças de três a dez anos (Educação Infantil e Ensino Fundamental), possuindo em cada sala em média 15 alunos/as (Instituição "F"). Ela possui amplo
5 Os dados coletados a partir dos encontros e através das observações das crianças nas duas instituições foram feitos pela autora deste texto.

6 Nome dado às Instituições de Educação Infantil na cidade de João Pessoa (PB).

7 O quadro docente é composto, em sua totalidade, por mulheres. 
espaço físico, permitindo uma variedade de uso por parte das crianças e suas professoras ${ }^{8}$. Usualmente, as atividades diárias giram em torno de desenvolvimento de projetos, leituras, ida ao parque e à brinquedoteca e alimentação.

As crianças pertencem a estratos sociais diferentes. As famílias que têm filhos/as na primeira instituição têm renda mensal em torno de um salário mínimo (R\$ 998, $0^{9}$ ); na outra escola as famílias vivem em melhor condição financeira, com renda variando entre dois a quatro salários mínimos.

Em relação aos seus níveis de desenvolvimento, a partir da concepção piagetiana (CAVICCHIA, 2001), as crianças estavam no estágio pré-operatório, marcado pelo forte presença da função simbólica e representativa, num período de ampliação da linguagem. Isso explica o interesse de todas elas por histórias envolvendo faz de conta e uso da imaginação. Em relação à linguagem, em geral as crianças se comunicavam bem; em virtude do grande número na Instituição "M", o diálogo entre elas e durante a mediação, eram bastante difíceis, tendo em vista que todos/as queriam falar ao mesmo tempo. Desse modo, a interação e expressão das crianças ocorreu de modo satisfatório na instituição " $F$ ", sendo possível verificar com mais acuidade seu repertório linguístico (BUSCH, 2015), apresentando-se amplo e diversificado, considerando o período de desenvolvimento assinalado. Também havia diferenças quanto ao desempenho no uso do código escrito, com uma maior apropriação entre as crianças da instituição " $F$ ".

Houve conflitos em relação aos brinquedos, ao material escolar, ao espaço na sala e durante as brincadeiras, nas duas instituições, mas com maior frequência entre as crianças da Instituição “M”, reforçados, portanto, pelo exíguo espaço nessa instituição destinado às demandas de interação e partilha das crianças ali atendidas.

Foram realizados quatro encontros com as crianças da instituição "M", e três encontros com as da Instituição "F" ${ }^{\prime \prime}$. Segue abaixo quadro demonstrativo das atividades realizadas em cada instituição:
8 Na Educação Infantil o quadro de professores também é composto majoritariamente por mulheres.

9 Valor referente ao ano de 2019.

10 A diferença no número de encontros entre as turmas foi devido a dificuldade em encaixar as atividades do estudo com a rotina das salas de referência. 
Quadro o1 - Atividades realizadas com as crianças.

\begin{tabular}{|c|c|c|c|}
\hline Atividades & Inst. M & Inst. F & Objetivos \\
\hline $\begin{array}{c}\text { Roda de conversa sobre brinquedos e brincadeiras } \\
\text { preferidos }\end{array}$ & $\mathrm{X}$ & $\mathrm{X}$ & $\begin{array}{c}\text { Conhecer o universo cultural das crianças } \\
\text { a partir dos tipos de brincadeiras/ } \\
\text { brinquedos que dispunham. }\end{array}$ \\
\hline Leitura de livros infantis & $\mathrm{X}$ & - & $\begin{array}{c}\text { Conversar sobre os desejos das crianças; } \\
\text { verificar a presença/ausência de } \\
\text { elementos de consumo. }\end{array}$ \\
\hline Interação individual com um celular & $\mathrm{X}$ & $\mathrm{X}$ & $\begin{array}{c}\text { Identificar os interesses das crianças ao } \\
\text { usarem o celular, o quê e como acessam. }\end{array}$ \\
\hline $\begin{array}{c}\text { Apresentação de imagens e símbolos da internet e } \\
\text { de alguns YouTubers. }\end{array}$ & $\mathrm{X}$ & $\mathrm{X}$ & $\begin{array}{c}\text { Verificar a identificação de imagens e } \\
\text { símbolos midiáticos e dos YouTubers } \\
\text { apresentados. }\end{array}$ \\
\hline $\begin{array}{c}\text { Brincar livre com pelúcias, carrinhos, fantoches, } \\
\text { fantasias, celulares, máquinas fotográficas, } \\
\text { máquina filmadora, gravador, computador }{ }^{11} \text {. }\end{array}$ & $\mathrm{X}$ & $\mathrm{X}$ & $\begin{array}{c}\text { Observar a interação das crianças com os } \\
\text { brinquedos disponibilizados. }\end{array}$ \\
\hline \multicolumn{2}{|c}{}
\end{tabular}

Fonte: Elaborado pela autora

Os encontros com as crianças apontaram elementos configuradores de um processo de midiatização da pequena infância na relação com os brinquedos e as brincadeiras, com o consumo, a internet, o YouTube e os YouTubers.

\section{Elementos indicadores da midiatização da infância}

A presença da midiatização entre as crianças pré-escolares foi verificada a partir dos seguintes indicadores: 1 . Sobre o que disseram as crianças sobre seus brinquedos e brincadeiras; 2. Dos brinquedos que desejam; 3. Das escolhas de brinquedos dentre os disponibilizados durante os encontros; 4. Pela identificação de símbolos e imagens; 5. Pelo acesso à internet e a preferência por canais de YouTubers.

Nos diálogos com as crianças sobre seus brinquedos e brincadeiras, foi comum entre os dois grupos a indicação de brinquedos marcados por representações simbólicas decorrentes de narrativas audiovisuais, como filmes, desenhos animados, programas de TV, etc., capitalizadas pela publicidade e propaganda destinadas ao público infantil. Assim, dentre os brinquedos tradicionais como bola e boneca (com forte demarcação de gênero), as crianças enfatizaram determinadas marcas nos brinquedos de suas preferências, como o carrinho da "Hotwheels" e super heróis da Marvel (Homem Aranha, Batman, Homem de Ferro) entre os meninos e bonecas "Lol" entre as meninas. Tais marcas povoam o imaginário infantil, mediando suas formas de brincar, dando significados, mesmo que não únicos, a essa prática.

As crianças apontaram, portanto, a relação direta com o universo midiático que seus brinquedos possuíam, especialmente carregados de significados, muitas vezes
11 Os aparelhos eletrônicos disponibilizados estavam avariados. 
outorgados pelas marcas que os acompanham (KLEIN, 2003). Os brinquedos citados pelas crianças não são meros objetos: "são ícones infantis mercantilizados" (MOMO, 2010, p. 82), elementos simbólicos que denotam processos de midiatização do ato de brincar.

Um outro aspecto indicador de uma pequena infância midiatizada, diz respeito aos desejos de consumo das crianças da pré-escola. Após a leitura de uma história que discorria acerca de uma criança que queria um "burrinho azul" ${ }^{12}$, os meninos disseram que gostariam de ganhar bolas, skate, bonecos de super-heróis, slime, espadas e armas e as meninas referiram a bonecas, especialmente a "Lol". Denota-se nas escolhas das crianças a padronização de identidades de gênero (SANDINI, 2017; FINCO, 2003), também presente nos discursos veiculados pelas mídias, acionando "formas de subjetivação" (FELIPE, 2006, p. 07), que contribuem para a constituição do modo de ser/estar das crianças.

Inseridas em um contexto de intensa circulação de informações mediado pela tecnologia, não é incomum verificar o interesse das crianças por alguns aparelhos eletrônicos, especialmente o tablet. Este, bastante citado pelas crianças da Instituição "M" como objeto de desejo, já era de uso habitual pela maioria das crianças da escola F. Em uma sociedade de consumo, como aponta Lipovetsky (2006, p. 2), "os mais desfavorecidos também são hiper consumidores ${ }^{13}$, embora apenas na cabeça".

Outros elementos indicadores de uma pequena infância midiatizada foram observados a partir das brincadeiras livres ${ }^{14}$ das crianças. Disponibilizamos brinquedos variados para que elas interagissem entre si e com os objetos (pelúcias, fantoches, carros, aparelhos eletrônicos danificados e já sem uso prático (celulares, câmera fotográfica, filmadora, notebook), bayblade, capa do Batman e o "Xerife Woody", (boneco/personagem do filme "Toy Story").

Desses brinquedos, os mais disputados eram os aparelhos celulares, o notebook e a câmera filmadora. De um lado, artefatos tecnológicos que para Momo (2007, p. 231) "geralmente proporcionam prestígio para quem os possui bem como promovem a inscrição em uma cultura globalmente reconhecida"; de outro, ícones (materiais ou não) da indústria do entretenimento voltados para o público infantil. Sobre isso, Momo assinala que "mais do que consumir materialidades, consumimos/comercializamos marcas, logomarcas e ícones (MOMO, 2010, p. 10).

A posse dos celulares trazidos gerava muitos conflitos entre as crianças, exigindo constante mediação dos adultos para contorná-los. Muitas queriam apenas segurar os aparelhos; uma delas insistiu em levar para casa para que seu pai o consertasse, pois, segundo ela, poderia "brincar de
12 Trata-se do livro "O Burrinho Azul" de Cecília Meireles.

13 Ao discutir sobre o conceito de pós-modernidade, Lipovetsky aponta que esse é um período que deve ser considerado de transição para o que ele chama de "tempos hipermodernos". A alusão ao termo hiper se dá por considerar que as características do mundo moderno alcançam seu estado mais elevado.

14 As brincadeiras livres se diferenciam das brincadeiras dirigidas . Essas, costumam ter um propósito de ensinar algo, a partir de um planejamento intencional; as brincadeiras livres se caracterizam pela autonomia da criança na construção do seu percurso lúdico. (PARÂMETROS NACIONAIS DE QUALIDADE PARA A EDUCAÇÃO INFANTIL, 2006). 
verdade". Nas brincadeiras das crianças, os celulares eram usados para "tirar self", fotos dos colegas e da professora, "buscar" músicas no YouTube, num processo de imitação de práticas sociais em voga.

Com mais de um smartphone por habitante, o Brasil possui 230 milhões de celulares ativos em 2019, segundo dados de pesquisa da Fundação Carlos Chagas (MEIRELLES, 2019). As afirmações das crianças de que gostavam de "jogar joguinho de celular", de jogar Minecraf "no celular da vovó", revelam que têm acesso aos aparelhos dos celulares dos pais ou de familiares e através deles acedem a narrativas, paisagens, imagens e linguagens disponíveis no mundo da internet.

O reconhecimento pelas crianças de quatro e cinco anos de símbolos usualmente utilizados na internet (Google, YouTube, Facebook, Instagram) é também um indicador da presença das mídias em seus cotidianos. A maioria sequer sabia pronunciar os nomes das imagens apresentadas, a exemplo do Instagram, dito pelas crianças como o lugar "prá por foto", algumas reportando a práticas de adultos de referência, especialmente a mãe.

A identificação dos símbolos demonstrado por uma criança da Instituição " $F$ ", que de forma espontânea juntou cones com as cores do Google Chrome e mostrou à professora o seu feito, aponta familiaridade com a internet. Para Maffesoli (1995) isso denota a existência de um "mundo imaginal", onde a imagem, o simbólico e o imaginário configuram e se interpõem na sociedade atual. Para o autor, é no compartilhamento de imagens, símbolos e rituais que se dá a coesão dos elementos fragmentados na sociedade. Trata-se da prevalência da aparência "que gera todos os fenômenos estéticos que delimitam a cultura moderna" (MAFFESOLI, 1998b, p. 82).

Entre as crianças das Instituições "M" e "F", o YouTube foi o símbolo mais reconhecido. Com o encolhimento da oferta de uma programação direcionada às crianças na TV aberta brasileira (FILHO, 2015), o acesso a conteúdos por crianças com menor poder aquisitivo se dá pela internet; além dessa via, as demais acedem através dos canais pagos. Os desenhos mais citados pelas crianças da Instituição "M" foram: Batalhas de Bayblade, Transformers e super heróis. Dora, Princesa Sofia, Jovens Titãs, Patrulha Canina, Bonecos de Pano e Fada foram os mais indicados na Instituição "F"15.

A busca e o acesso pelas crianças a uma programação infantil via YouTube levanta questões acerca da contribuição do mesmo na configuração de modos de ser e estar da criança. Assim, de um lugar onde se produz e circula narrativas, linguagens, formatos, inseridos numa perspectiva espetacularizada (DALETHESE, 2017), o YouTube também
15 Caberia um estudo mais aprofundado para identificar e analisar o porquê das diferenças em relação aos desenhos animados mais acessados pelos dois grupos de crianças. 
pode "convocar" as crianças para o consumo (MELO, 2017), bem como ser "um lugar de crianças", mesmo sem ter sido pensado para elas, especificamente (TOMAZ, 2017).

Usado também pelas crianças envolvidas nesse estudo para aceder a jogos e assistir vídeos de YouTubers, a plataforma de compartilhamento de vídeos se torna espaço de fruição para elas. Desse modo, "tocar telas é brincar" (COUTO, 2013, p. 990), o que sinaliza transformações nas práticas lúdicas da criança contemporânea (HJARVARD, 2013).

O brincar mediado pelo YouTube ganha novos contornos quando emerge a figura do YouTuber, seja através de canais apresentados por crianças (YouTubers mirins ${ }^{16}$ ) ou por pessoas adultas.

Entre as crianças participantes desse estudo, os YouTubers Lucas Neto e Felipe Neto eram os mais conhecidos. Quase por unanimidade, o primeiro é o mais assistido (especialmente da instituição "M"); durante o diálogo com as crianças, os personagens que compõem esse canal são citados nominalmente e as músicas cantadas em coro. Questionados sobre o que mais gostavam do YouTuber, responderam que "ele brinca das mesmas coisas que eu", "quando eu era grande, eu gostava de brincar do jeito dele". Tal identificação pode ser explicada a partir dos eixos estruturadores das culturas da infância: a interatividade, a ludicidade, a fantasia do real e a reiteração (SARMENTO, 2004). Tais elementos, de um modo ou de outro, se encontram presentes na relação que os YouTubers estabelecem com as crianças.

Não foi possível adentrar nas questões que cada indicador de uma pequena infância midiatizada aqui apresentada, engendra. Contudo, é possível identificar a partir das crianças com as quais mantivemos contato, a inserção das mesmas, desde cedo, à culture screnn (LEMISH, 2015), que, mediada pelas tecnologias e pelas mídias, provoca a interação entre as linguagens, conteúdos, comportamentos dos pequenos, com as mídias (BELLONI, 2009). Com o acesso a esse universo, amplia-se o processo de midiatização da infância, o que provoca mudanças em seu modo de ser e estar.

\section{Considerações finais}

Nesse texto, resultado de um estudo exploratório com crianças de quatro e cinco anos de idade, discutimos alguns elementos indicadores de um processo de midiatização da pequena infância. A partir de diálogos com grupos de crianças, mas também através de contatos individuais com alguma delas, pudemos verificar a presença desse processo em seus desejos, seus modos de interagir com brinquedos, na linguagem, em seus interesses.
16 No Brasil há muitos canais de YouTubers protagonizados por crianças que "contam com enorme popularidade entre os pares, desafiam os limites entre amadorismo e profissionalização, são reconhecidas pela indústria como influenciadoras digitais e lucram financeiramente com os vídeos nos quais participam" (MARÔPO; VITORINO; PEREIRA DE MIRANDA, 2018, p. 176). 
Foram os seguintes elementos identificados: 1. Desejo de possuir brinquedos, especialmente os que carregam marcas fortalecidas pelo mercado publicitário destinado ao público infantil; 2. Os desejos de consumo das crianças por tablets e celulares; 4. A identificação de símbolos do universo midiático; 5. O brincar virtual através do YouTube, mas também mediado por YouTubers, pares ou não.

Os dois grupos participantes deste estudo apresentam inúmeras semelhanças. As crianças utilizam os celulares de seus pais ou familiares para acessar a internet, desejam as mesmas marcas de brinquedos (embora com forte demarcação de gênero), acedem à internet para jogar e/ ou assistir ao YouTube (sendo o canal do YouTuber Lucas Neto o mais citado entre elas).

Por outro lado, encontramos distintas realidades sociais, verificadas especialmente a partir do poder aquisitivo das famílias das crianças e pelas diferentes oportunidades no tocante às instituições às quais frequentam, já que se distanciam pelo número de crianças por sala, ambientes e materiais ofertados e formação das professoras. No contexto formal de educação, tais diferenças são visíveis a partir das interações que as crianças estabelecem entre seus pares e entre os adultos, pautadas por conflitos e dificuldades no estabelecimento de diálogos que possibilitem a ampliação do nível cultural das mesmas.

Em relação ao acesso midiático, as diferenças se apresentaram em relação aos desenhos animados citados (especificamente quanto aos tipos escolhidos), no maior acesso ao YouTube e ao canal do Lucas Neto, com marcante presença entre as crianças da instituição "M".

Entre diferenças e similitudes, não é possível desconsiderar o modo próprio das crianças se apropriarem e interagirem com o que lhes é ofertado. A partir das condições e "conteúdos" que lhes são dados, elas se apropriam e constituem suas representações simbólicas acerca do vivido (SARMENTO; PINTO, 1997). Nesse aspecto, foi marcante a fala de uma criança que, em diálogo com outra que dizia não ter luz em sua casa (denotando ausência de condições mínimas de vida), afirmava ser assim "porque Jesus queria”. Há aqui demarcadores sociais e culturais que interferem na compreensão da criança, mas também revela a sua capacidade de, mesmo com quatro anos de idade, compreender, a seu modo, uma realidade tão difícil, numa "reprodução interpretativa" (CORSARO, 2002).

Através dos dados coletados é possível afirmar que existe um forte processo de midiatização da pequena infância, que se revela a partir dos seus interesses por determinados brinquedos, o desejo pela posse de um celular, mesmo que para fazer parte de sua brincadeira, a expansão do uso da internet para assistir desenhos animados, mas 
também para brincar virtualmente, o "encantamento" das crianças pelos YouTubers, muitos deles com idades aproximadas as das suas audiências.

Nota-se que a disseminação das tecnologias e mídias digitais e o acesso cada vez mais cedo às suas narrativas têm promovido mudanças naquilo que é considerado próprio da infância, que é sua cultura lúdica (BROUGÉRE, 1998). Esta vai se constituindo a partir dos conteúdos culturais ofertados, sendo ressignificados pelas crianças a partir do lugar social que ocupa e dos dispositivos (tecnológicos, midiáticos, culturais, etc) que dispõem.

O entrelaçamento entre a infância e os meios de comunicação cria, por um lado, uma relação entre as crianças e a cultura global marcadamente mercadológica e consumista. Por outro, criam também possibilidades de acesso a uma gama de contextos midiáticos que podem ampliar e diversificar seus repertórios culturais (LIVINGSTONE, 2014).

Isso reforça a necessidade de considerar as instituições formais de atendimento à pequena infância como importantes espaços para educação das crianças no sentido de ampliar suas capacidades de ressignificação do que lhes é ofertado, com o uso de diferentes linguagens, inclusive as midiáticas. Eis o desafio posto para os educadores na atualidade.

\section{Referências}

BABBIE, Earl. The practice of social research. Belmont: Wadsworth Pub, 1986.

BARBOSA, Maria Carmem Silveira. Especificidades da ação pedagógica com os bebês. Anais do I Seminário Nacional: Currículo em Movimento - Perspectivas Atuais, Belo Horizonte, nov./2010. Disponível em: http:// portal.mec.gov.br/docman/dezembro-2010-pdf/7154-2-2-artigo-mec-acao-pedagogica-bebes-m-carmem/file. Acesso em: 16 set. 2019.

BELLONI, Maria. Luiza. O que é Sociologia da infância? Campinas, SP: Autores Associados, 2009.

BRASIL. Lei n. 9.394, de 20 de dezembro de 1996. Estabelece as Diretrizes e Bases da Educação Nacional. Diário Oficial da União, Brasília, DF, 23 dez. p. 27894, 1996.

. Ministério da Educação, Secretaria da Educação Básica. Parâmetros Nacionais de Qualidade para a Educação Infantil, v. 2, Brasília, DF, Brasil, 2006.

Ministério da Educação. Secretaria da Educação Básica. Diretrizes Curriculares Nacionais da Educação Infantil. Brasília, DF, Brasil, 2009. 
BRITO, Rita; DIAS, Patrícia. Pais, filhos e tecnologias digitais móveis: percepções de utilização e critérios para escolha de atividades. In.: BRITO, R.; DIAS P. (Coord.). Crianças, famílias e Tecnologias. Que desafios? Que caminhos? CIED (Centro Interdisciplinar de Estudos Educacionais) Escola Superior de Educação do Instituto Politécnico de Lisboa, 2019.

BROUGÈRE, Gilles. A criança e a cultura lúdica. Revista da Faculdade de Educação, v. 24, n.(2), p. 103-116, 1998. Disponível em https://dx.doi.org/10.1590/So10225551998000200007. Acesso em: 14 out. 2019.

BUCKINGHAM, David. Repensando a criança-consumidora: Novas Práticas, Novos Paradigmas. Comunicação, Mídia e Consumo, São Paulo, v. 9 n. 25, p. 43-72, 2012.

BUSCH, Brigitta. Linguistic Repertoire and and Spracherleben, the lived experience of language. Urban Language \& Literacies, Paper 148, University of Viena, 2015. Disponível em: https://pdfs.semanticscholar. org/dcfa/d7c1e143d6aef2429fb7a04eo0385f4a9d86. pdf?_ga $=2.22831986 .894717620 .1574441902-$ 899767648.1574441902 Acesso em: o1 out. 2019.

CASTELS, Manuel. A sociedade em rede. 11. ed. Tradução de Roneide Venâncio Majer. São Paulo: Ed. Paz e Terra, 1999.

CORSARO, William. A reprodução interpretativa no brincar ao "faz de conta" das crianças. Educação, Sociedade \& Culturas, n. 17, 2002.

COUTO, Edvaldo Souza. A infância e o brincar na cultura digital. Perspectiva, Florianópolis, v. 31, n. 3, p. 897-916, set./dez., 2013.

DALETHESE, T. R."Faz de conta que todos nós somos youtubers": crianças e narrativas contemporâneas. Dissertação de Mestrado, Universidade Federal do Estado do Rio de Janeiro, Brasil, 2017. Disponível em: http://www.unirio.br/ppgedu/DissertaoPPGEduTHAMYRESRIBEIRODALETHESE.pdf. Acesso em: 03 set. 2019.

DIAS, Patrícia.; BRITO, Rita. Crianças (o-8 anos) e Tecnologias Digitais. Coordenado pelo Joint Research Center da Comissão Europeia. CECC (Centro de Estudos de Comunicação e Cultura), Lisboa, 2015.

CAVICCHIA, Durlei de Carvalho. O desenvolvimento da criança nos primeiros anos de vida. Acervo Digital da UNESP, 2001. Disponível em: https://acervodigi- 
tal.unesp.br/bitstream/123456789/224/1/o1d11to1.pdf. Acesso em: 18 nov. 2019.

FELIPE, Jane. Representações de gênero, sexualidade e corpo na mídia. Revista Tecnologia e Sociedade, v. 2, n. 3, Curitiba, PR, 2006.

FINCO, Daniela. Relações de gênero nas brincadeiras de meninos e meninas na Educação Infantil. Pro-Posições, v.14, n.3 (42), Campinas, SP, set/dez., 2003.

FILHO, Laurindo Lalo Leal. O fim dos programas infantis na TV. Carta Maior, 2015. Disponível em: https://www. cartamaior.com.br/?/Coluna/O-fim-dos-programas-infantis-na-TV/33187 Acesso em: 10 nov. 2019.

GIL, Antonio Carlos. Métodos e técnicas de pesquisa social. 6. ed. São Paulo: Atlas, 2008.

HEPP, Andreas. As configurações comunicativas de mundos midiatizados: pesquisa da midiatização na era da "mediação de tudo". Matrizes. São Paulo, v. 8, n. 1, p. 45-64, jan./jun., 2014.

HJARVARD, Stig. A midiatização da cultura e da sociedade. Editora Unisinos, São Leopoldo/RS, 2013.

HJARVARD, Stig. Midiatização: conceituando a mudança social e cultural. Matrizes, v. 8, n. 1, São Paulo, jan./jun., 2014.

HJARVARD, Stig. Da mediação à midiatização: a institucionalização das novas mídias. Parágrafo, v. 2, n. 3, jul./ dez., 2015.

HJARVARD, Stig. Olhando além do campo: o desenvolvimento da agenda de pesquisa da midiatização. Entrevista com Stig Hjarvard por Nicolás Llano Linares. Matrizes. São Paulo/SP, V.10 - nº 1 jan./abr., 2016.

IZCI, Burcu; JONES, Ithel; BAHCEKAPILI, Tugba; ALKTEBI, Latifa; BAKIR, Eda. Youtube \& young children: research, concerns and new directions. In.: BRITO, Rita; DIAS Patrícia. (Coord.). Crianças, famílias e tecnologias. que desafios? que caminhos? CIED (Centro Interdisciplinar de Estudos Educacionais) Escola Superior de Educação do Instituto Politécnico de Lisboa, 2019.

LEMISH, Dafna. Children and media: a global perspective. John Wiley \& Sons, 2015.

LIPOVETSKY, Gilles. O hedonismo fraturado. Folha de S. Paulo, São Paulo, 2006. 
LIVINGSTONE, Sonia. On the mediation of everything: ICA presidential address 2008. Journal of communication, v.59, n1, p. 1-18, 2009.

The mediatization of childhood and education: reflections on The Class. In KRAMP, L., CARPENTIER, N., HEPP, A., TOMANIC-TRIVUNDZA, I., NIEMINEN, H., KUNELIUS, R., OLSSON, T., SUNDIN, E. \& KILBORN, R. (eds.). Media Practice and Everyday Agency in Europe. Bremen: Edition Lumière, 2014.

LIUBINIENĖ, Vilmanté; KASPERAVIČIEN, Ramuné. Young children's engagement with digital technologies in the family context: a case of Lithuania. In.: BRITO, Rita; DIAS Patrícia (Coords.). Crianças, famílias e tecnologias. que desafios? que caminhos? CIED (Centro Interdisciplinar de Estudos Educacionais) Escola Superior de Educação do Instituto Politécnico de Lisboa, 2019.

KLEIN, Naomi. Sem logo: a tirania das marcas em um planeta vendido. Trad. Ryta Vinagre. Rio de Janeiro: Record, 2003.

KRAMER, Sonia. As crianças de o a 6 anos nas políticas educacionais no Brasil: Educação Infantil e/é Fundamental. Educação e Sociedade, Campinas, v. 27, n. 96 - Especial, p. 797-818, out. 2006. Disponível em: http://www. cedes.unicamp.br. Acesso em: 23 set. 2019.

MAFFESOLI, Michel. A contemplação do mundo. Tradução de Francisco Franke Settineri. Porto Alegre: Artes e Ofícios, 1995.

MAFFESOLI, Michel. Elogio da razão sensível. Trad. de Albert Chistophe M. Stuckenbruck. Petrópolis: Vozes, 1998b.

MARÔPO, L. VITORINO, S. I.; PEREIRA DE MIRANDA, N. Meninas no YouTube: participação, celebrização e cultura do consumo. Estudos em Comunicação v. 1, n. 26, 175-195. DOI: 10.20287/ec.n26.v1.a10, 2018.

MEIRELleS, Fernando de Souza. $3^{\mathbf{a}}$ Pesquisa Anual do Uso de TI nas Empresas, 2019. Disponível em: http://fgvcia.eaesp.fgv.br/sites/fgvcia.eaesp.fgv.br/files/ arquivos/u11/pesti2019fgvciappt_2019.pdf. Acesso em: 02 dez. 2019.

MELO, Darcyane Rodrigues de. Youtube: Dispositivo que Convoca Crianças Contemporâneas ao Consumo, 2017. Disponível em: https://www.sbece.com.br Acesso em: 24. set.2019. 
MINAYO, Maria Cecília de Souza (org.). Pesquisa Social. Teoria, método e criatividade. 18. ed. Petrópolis: Vozes, 2001.

MOMO, Mariangela. Mídia e consumo na produção de uma infância pós-moderna que vai à escola. Tese de doutorado. Universidade Federal do Rio Grande do Sul, Porto Alegre, Brasil, 2007.

MOMO, Mariangela. Mídia e consumo na produção da infância pós-moderna. REU, Sorocaba, SP, v. 36, n. 1, p. 67-87, jun., 2010.

PONTE, Cristina. Crianças \& Media: pesquisa internacional e contexto português do século XIX à actualidade. Imprensa de Ciências Sociais, Portugal, 2012.

PONTE, C.; SIMÕES, J.A.; CASTRO, T.S.; BATISTA, S.; JORGE, A. Educando entre ecrãs. In.: PONTE, Cristina. (coord.). Boom digital? Crianças (3-8 anos) e ecrãs. ERC - Entidade Reguladora para a Comunicação Social, Lisboa, 2018.

PONTE, C.; CASTRO, T.S.; BATISTA, S. A influência familiar nas atividades digitais de crianças portuguesas de 6-8 anos. In.: Educação para o desenvolvimento. p. 4657. jul., 2018.

SANDINI, Sabrina Plá. Brinquedos de meninas e brinquedos de meninos: a normatização da questão de gênero na escola, 2017. Disponível em https:// educere.bruc.com.br/arquivo/pdf2017/23729_12158.pdf Acesso em: 04. nov. 2019.

SAPSAĞLAM. Öskan. Social media awareness and usage in preschool children, International Journal Of Eurasia Social Sciences, v. 9, Issue: 31, p. 728-746, 2018. Disponível em http://www.ijoess.com/DergiTamDetay.aspx?I$\mathrm{D}=2233 \&$ Detay=Ozet . Acesso em: 04 nov. 2019.

SARMENTO, M. J.; PINTO, M. As crianças e a infância: definindo conceitos delimitando o campo. In: PINTO, M.; SARMENTO, M. J. (coords.). As crianças: contextos e identidades. Braga, Portugal: Centro de Estudos da Criança, 1997.

SARMENTO, M. J. As culturas da infância nas encruzilhadas da $2^{\mathrm{a}}$ modernidade. In: SARMENTO, M. J.; CERISARA, A. B. Crianças e miúdos: perspectivas sociopedagógicas da infância e educação. Porto, Portugal: Edições ASA, 2004. 
SATUF, I. SANTOS, R. R. A., MENEZES, A. F. \& FERNANDES, B. S. Três perspectivas sobre a midiatização e suas implicações na pesquisa em Comunicação. Temática. v. XV, n. 5. maio 2019. NAMID/UFPB. Disponível em: http://periodicos.ufpb.br/ojs2/index.php/tematica Acesso em: 19 nov. 2019.

SIROTA, Régine. Infância: evolução do objeto e do olhar. Cadernos de Pesquisa, ${ }^{0}$ 112, p. 7-31, mar., 2001.

TOMAZ, Renata. O. O que você vai ser antes de crescer? - Youtubers, Infância e Celebridade. Tese de Doutorado em Comunicação e Cultura, Universidade Federal do Rio de Janeiro, Escola de Comunicação. Rio de Janeiro, 2017.

Enviado em: 20-05-2020

Aceito em: 23-08-2020

Publicado em: 30-10-2020 